\title{
Formação e atuação do professor orientador de estágio supervisionado na licenciatura em educação física
}

\author{
Antonio Evanildo Cardoso de Medeiros Filho ${ }^{1}$ \\ Antonio Germano Magalhães Junior ${ }^{2}$
}

\section{Resumo}

Este estudo analisou as produções científicas relacionadas à formação e atuação do professor orientador de Estágio Curricular Supervisionado nos cursos de licenciatura em Educação Física. Foram considerando os trabalhos publicados entre 2008 e 2020, disponíveis na base de dados da Scientific Electronic Library Online (SciELO), no Portal de Periódicos CAPES, no repositório da Biblioteca Digital Brasileira de Teses e Dissertações (BDTD) e no Catálogo de Teses e dissertações da CAPES. As produções selecionadas problematizam a importância das supervisões para atuação do estagiário; relação professor orientador-estagiário-professor supervisor; qualidade das orientações do professor orientador; frequência de supervisões ou orientações; e condições de trabalho do professor orientador. Palavras-chave: Educação Superior; Professor; Aprendizagem; Estado da Questão.

Education and performance of the supervised internship guiding teacher in the physical education degree

\section{Abstract}

This study analyzed the scientific productions related to the formation and performance of the guiding teacher in the Supervised Curriculum Internship in the Physical Education courses. There were considered the studies published between 2008 and 2020, available in the Scientific Electronic Library Online (SciELO) database, CAPES Periodicals Portal, repository of the Brazilian Digital Library of Theses and Dissertations (BDTD), and the CAPES Theses and Dissertations Catalogue. The selected productions question the importance of supervision for the interns' performance; the relation guiding teacher, interns and supervisor teacher; quality of the supervisor teacher orientations; frequency of supervisions or orientations; and working conditions of the supervisor teacher.

Keywords: Higher Education; Teacher; Learning; State of Question.

\section{Considerações iniciais}

A presente investigação discute as produções científicas sobre a formação e atuação do professor orientador ${ }^{3}$ de Estágio Curricular Supervisionado (ECS) nos cursos de licenciatura em Educação Física. Este trabalho se inicia por estas "considerações iniciais", onde iremos apresentar as finalidades e contribuições do Estado da Questão (EQ) na elaboração de projetos

\footnotetext{
${ }^{1}$ Universidade Estadual do Ceará, Fortaleza, evanildofilho17@gmail.com.

2 Universidade Estadual do Ceará, Fortaleza, germano.junior@uece.br.

3 Denominamos neste manuscrito o professor do curso de formação como "professor orientador" e o da escola como "professor supervisor".
} 
de pesquisa; seguida dos "caminhos percorridos ao encontro da literatura especializada"; "análises dos artigos: SciELO e portal de periódico CAPES"; "análises das dissertações e teses: BDTD e catálogo de teses e dissertações da CAPES"; e finalmente as "considerações finais".

Os professores pesquisadores Nóbrega-Therrien e Therrien (2010) defendem que a elaboração do EQ na produção de trabalhos acadêmicos, como monografia, dissertação de mestrado e tese de doutorado, auxilia estudante/pesquisador na aproximação da literatura já existente sobre o tema ou objeto que se pretende investigar. Estas produções acadêmicocientíficas já publicizadas, contêm diferentes perspectivas metodológicas e epistemológicas. Desse modo, oportuniza a ação reflexiva e apresentação de novos questionamentos e direcionamentos para o delineamento da pesquisa, em nosso caso, da tese. Nessa perspectiva, Nóbrega-Therrien e Therrien (2010, p.34) apontam que o EQ tem como um de suas finalidades "[...] levar o pesquisador a registrar, com suporte em um rigoroso levantamento bibliográfico, como se encontra o tema ou o objeto de sua investigação no estado atual da ciência ao seu alcance".

Para elaboração do EQ é necessário planejamento, criatividade, dedicação, tempo, atenção dentre outras aptidões que o estudante/pesquisador precisa manifestar para obter êxito, ou seja, "colher e usufruir dos frutos" do EQ (NÓBREGA-THERRIEN; THERRIEN, 2010). Caso contrário, corre o risco de comprometer a organização das informações coletadas na literatura especializada e, principalmente, na ação reflexiva sobre os achados. Nessas condições, o EQ pouco poderá contribuir no delineamento dos objetos, categorias centrais e problema da investigação.

Destarte, a intenção de elaborarmos o presente EQ surgiu pela necessidade de delineamento dos objetos de investigação, formulação das categorias teóricas e dos aspectos metodológicos. Essa necessidade foi despertada após a realização de leituras e discussões sobre algumas obras clássicas sobre atuação e formação de professores (GAUTHIER et al., 1998; GAUTHIER; BISSONNETTE; RICHARD, 2014) e ECS (PICONEZ et al. 2012; PIMENTA; LIMA, 2017; ZABALZA, 2014).

Somado a isso, esse interesse foi potencializado a partir da leitura do escrito de Boote e Beile (2005), intitulado a Scholars before researchers: on the centrality of the dissertation literature review in research preparation, assim com a leitura da obra intitulada "Pesquisa em 
Educação: métodos e epistemologias" (GAMBOA, 2012).

Boote e Beile (2005) defendem que a qualidade de uma tese de doutorado é précondicionada de uma sofisticada revisão de literatura, uma vez que o estudante/pesquisador analisa o que já foi produzido, os pontos fracos e fortes dos estudos analisados e suas implicações teóricas e práticas. Já Gamboa $(2012$, p.66) relata sobre a necessidade de "ler e reler" outras pesquisas antes da elaboração do projeto de pesquisa. Esta ação permite o estudante/pesquisador identificar os "principais elementos, recuperar seus métodos e estratégias, descobrir suas rotas ocultas, revelar seus pressupostos e estruturas básicas". Para o autor, essa leitura permite a familiarização com as pesquisas sobre a temática a ser investigada.

Diante desses pressupostos, debrucemo-nos sobre as produções acadêmico-científicas a respeito da formação e atuação do professor orientador de ECS nos cursos de licenciatura em Educação Física. Para isso, traçamos um caminho e o percorremos sistematicamente para selecionar artigos, dissertações de mestrado e teses de doutorado sobre essa temática.

\section{Método: caminhos percorridos ao encontro da literatura especializada}

Iremos apresentar nesta seção os caminhos percorridos para seleção das produções científicas sobre a formação e atuação do professor orientador de estágio em cursos de licenciatura em Educação Física. Ressaltamos que tivemos como pergunta norteadora: Quais as produções científicas e o que elas discutem sobre a formação e atuação do professor orientador de ECS nos cursos de licenciatura em Educação Física?

Para viabilizar a seleção das produções científicas, delimitamos o nosso interesse pelos trabalhos escritos no idioma português e que foram publicados entre 2008 e 2020. A escolha do primeiro ano desse recorte temporal se deu em virtude de ser o ano de promulgação da Lei $\mathrm{n}$. 11.788, de 25 de setembro de 2008, a qual dispõe acerca dos estágios de estudantes (BRASIL, 2008); já o último, por ser o ano da realização das pesquisas/buscas nos sítios eletrônicos de trabalhos científicos.

As buscas nas respectivas bases de dados e repositórios foram realizadas entre os dias 27 de agosto de 2020 a 15 de setembro do mesmo ano. Essa ação foi dividida em dois momentos, sendo o primeiro a seleção de artigos científicos e o segundo de teses e dissertações. No primeiro 
bloco recorremos à base de dados da Scientific Electronic Library Online (SCiELO) ${ }^{4}$ e ao Portal de Periódicos CAPES ${ }^{5}$. Quanto ao segundo, consultamos a Biblioteca Digital Brasileira de Teses e Dissertações (BDTD) ${ }^{6}$ e o Catálogo de Teses e dissertações da CAPES 7 .

Utilizamos descritores reconhecidos pelo Thesaurus Brasileiro da Educação (BRASED), o qual se trata de "um vocabulário controlado que reúne termos e conceitos, extraídos de documentos analisados no Centro de Informação e Biblioteca em Educação (CIBEC), relacionados entre si a partir de uma estrutura conceitual da área" (BRASIL, 2020). Com o auxílio dos operadores booleanos, $A N D$ e $O R$, formulamos a seguinte equação: "Educação Física" AND "Licenciatura" AND "Estágio Supervisionado" $O R$ Estágio $O R$ "Supervisor de estágio8" $O R$ "Professor Orientador".

Antes de iniciarmos a apresentação dos resultados, cabe mencionarmos os filtros utilizados em cada base de dados e repositório. Na SciELO, utilizamos como filtro o "idioma português" e o "recorte temporal" (2008-2020). No Portal de periódicos da CAPES, além desses dois filtros, acrescentamos no "Tipo de recurso" apenas artigos, bem como o filtro "periódicos revisados por pares". Já no repositório da BDTD e no Catálogo de Teses e dissertações da CAPES utilizamos apenas o filtro "recorte temporal".

Para seleção dos artigos, dissertações e teses, seguimos o seguinte caminho, respectivamente, i) análise por título, ii) análise do resumo na intenção de perceber a relevância e coesão com temática aqui investigada e, iv) leitura do texto na íntegra para seleção dos trabalhos a ser analisados.

Podem ser consultados no Quadro 1 os caminhos percorridos até a seleção final dos trabalhos no sítio eletrônico da SciELO, Portal de periódicos da CAPES, Catálogo de Teses e dissertações da CAPES e BDTD.

\footnotetext{
${ }^{4}$ https://scielo.org/.

${ }^{5}$ https://www.periodicos.capes.gov.br/.

${ }^{6}$ https://bdtd.ibict.br/vufind/.

${ }^{7}$ https://www.periodicos.capes.gov.br/.

${ }^{8}$ Embora consideremos nessa investigação o professor supervisor aquele que recebe o estagiário na escola, optamos por inserir esse termo (professor supervisor) em virtude de que há estudos na literatura científica que utiliza essa terminologia para designar o professor do curso de formação, como exemplo, o estudo de Isse (2016), Scherer (2008) e Souza Neto, Sarti e Benites (2016).
} 


\section{HSE}

Quadro 1 - Caminhos percorridos até a seleção final dos trabalhos em cada sítio eletrônico.

\begin{tabular}{|c|c|c|c|c|c|c|c|}
\hline Sítios eletrônicos & 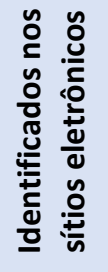 & 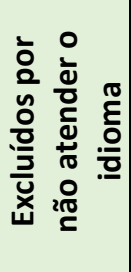 & 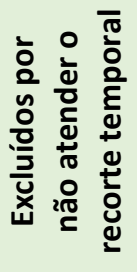 & 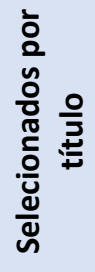 & 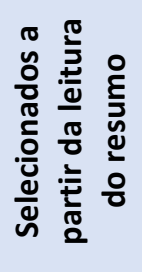 & 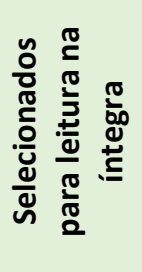 & 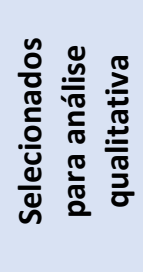 \\
\hline SCIELO & 59 & 10 & 1 & 4 & 4 & 3 & 3 \\
\hline $\begin{array}{c}\text { Portal de periódicos da } \\
\text { CAPES }\end{array}$ & 8262 & 3095 & 775 & 42 & 8 & 6 & 5 \\
\hline CTD da CAPES & 38 & 0 & 6 & 5 & 3 & 3 & 2 \\
\hline BDTD & 337 & 0 & 33 & 19 & 13 & 13 & 12 \\
\hline Total & 8696 & 3105 & 815 & 70 & 28 & 25 & 22 \\
\hline
\end{tabular}

Fonte: Os autores.

Podemos perceber no Quadro 2 que inicialmente foram encontrados 8696 trabalhos nos sítios eletrônicos, sendo a maioria artigos do Portal de periódicos da CAPES (8262 trabalhos). No entanto, foram excluídos 3105 por não atender o idioma português e 815 por não contemplar o recorte temporal. Dos 4776 foram selecionados 70 trabalhos $^{9}$ a partir do título que consideramos estar mais relacionado com a temática investigada. Após a leitura dos resumos foram excluídos 43 trabalhos e 5 após a leitura na íntegra, restando 22 trabalhos para análise qualitativa, especificamente, 8 artigos científicos, 9 dissertações de mestrado e 5 teses de doutorado.

\section{Análise dos artigos: SciELO e portal de periódico CAPES}

Considerando que já apresentamos o caminho que nos levou a, dentro de um universo de 8262 artigos (59 trabalhos na SCIELO e 8262 no Portal de periódicos da CAPES), selecionar os que possuem relação com a temática da tese (8 artigos), iremos agora descrevê-los quanto aos seus objetivos, aspectos metodológicos e principais resultados (ver Quadro 2).

\footnotetext{
${ }^{9}$ Eram 72 trabalhos, mas dois foram excluídos da BDTD em virtude de estar duplicado com os trabalhos do Catálogo de Teses e dissertações da CAPES.
}

Periódico Horizontes - USF - Itatiba, SP - Brasil - e021023 
Quadro 2 - Autor/es, ano, revista/periódico, Qualis CAPES e título dos artigos selecionados.

\begin{tabular}{|c|c|c|c|c|}
\hline $\begin{array}{c}\text { Autor/es } \\
\text { (ano) }\end{array}$ & $\begin{array}{c}\text { Sítio } \\
\text { eletrônico }\end{array}$ & Revista/periódico & $\begin{array}{l}\text { Qualis } \\
\text { CAPES }^{10}\end{array}$ & Título \\
\hline $\begin{array}{l}\text { Santos } \\
\text { (2019) }\end{array}$ & $\begin{array}{l}\text { Portal de } \\
\text { periódicos da } \\
\text { CAPES }\end{array}$ & $\begin{array}{c}\text { Caderno de Educação Física } \\
\text { e Esporte } \\
\text { Universidade Estadual do } \\
\text { Oeste do Paraná } \\
\text { (UNIOESTE) }\end{array}$ & C & $\begin{array}{l}\text { Estágio curricular supervisionado } \\
\text { em Educação Física: experiência } \\
\text { e implicações para a formação de } \\
\text { professores }\end{array}$ \\
\hline $\begin{array}{l}\text { Pereira et al. } \\
\qquad(2018)\end{array}$ & SCIELO & $\begin{array}{l}\text { Journal of Physical } \\
\text { Education } \\
\text { Universidade Estadual de } \\
\text { Maringá (UEM) }\end{array}$ & $\mathrm{A} 1$ & $\begin{array}{l}\text { Trajetória de estudantes na } \\
\text { formação inicial em Educação } \\
\text { Física: o estágio curricular } \\
\text { supervisionado em foco }\end{array}$ \\
\hline $\begin{array}{l}\text { Silva Júnior, } \\
\text { Both e } \\
\text { Oliveira } \\
\text { (2018) }\end{array}$ & SCIELO & $\begin{array}{c}\text { Journal of Physical } \\
\text { Education } \\
\text { Universidade Estadual de } \\
\text { Maringá (UEM) } \\
\end{array}$ & $\mathrm{A} 1$ & $\begin{array}{l}\text { Configurações e relações } \\
\text { estabelecidas no estágio } \\
\text { curricular supervisionado de } \\
\text { Educação Física }\end{array}$ \\
\hline $\begin{array}{l}\text { Almeida e } \\
\text { Moreira } \\
(2018)\end{array}$ & $\begin{array}{l}\text { Portal de } \\
\text { periódicos da } \\
\text { CAPES }\end{array}$ & $\begin{array}{c}\text { Revista Cocar } \\
\text { Universidade do Estado do } \\
\text { Pará (UEPA) }\end{array}$ & B1 & $\begin{array}{l}\text { Os saberes/conhecimentos } \\
\text { mobilizados pelos professores de } \\
\text { estágio curricular nos cursos de } \\
\text { licenciatura em Educação Física } \\
\text { no estado de mato grosso }\end{array}$ \\
\hline $\begin{array}{l}\text { Isbarrola e } \\
\text { Copetti } \\
\text { (2018) }\end{array}$ & $\begin{array}{l}\text { Portal de } \\
\text { periódicos da } \\
\text { CAPES }\end{array}$ & $\begin{array}{l}\text { Revista Exitus } \\
\text { Universidade Federal do } \\
\text { Oeste do Pará (UFOPA) }\end{array}$ & B2 & $\begin{array}{l}\text { Percepções de estagiários da } \\
\text { Educação Física sobre o Estágio } \\
\text { supervisionado na educação } \\
\text { infantil }\end{array}$ \\
\hline $\begin{array}{l}\text { Souza Neto, } \\
\text { Sarti e } \\
\text { Benites } \\
(2016) \\
\end{array}$ & $\begin{array}{l}\text { Portal de } \\
\text { periódicos da } \\
\text { CAPES }\end{array}$ & $\begin{array}{c}\text { Movimento } \\
\text { Universidade Federal do } \\
\text { Rio Grande do Sul (UFRGS) }\end{array}$ & $\mathrm{A} 2$ & $\begin{array}{l}\text { Entre o ofício de aluno e o } \\
\text { habitus de professor: os desafios } \\
\text { do estágio supervisionado no } \\
\text { processo de iniciação à docência }\end{array}$ \\
\hline $\begin{array}{l}\text { Zuluaga } \\
\text { (2015a) }\end{array}$ & $\begin{array}{l}\text { Portal de } \\
\text { periódicos da } \\
\text { CAPES }\end{array}$ & Lúdica pedagógica & B1 & 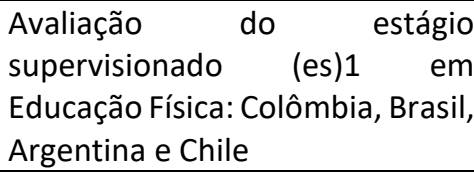 \\
\hline $\begin{array}{l}\text { Silva, Souza } \\
\text { e Checa } \\
\text { (2010) }\end{array}$ & SCIELO & $\begin{array}{l}\text { Motriz. Revista de } \\
\text { Educação Física } \\
\text { Universidade Estadual } \\
\text { Paulista (UNESP) }\end{array}$ & B1 & $\begin{array}{l}\text { Situação do estágio } \\
\text { supervisionado em IES privadas } \\
\text { da grande São Paulo }\end{array}$ \\
\hline
\end{tabular}

Fonte: Os autores.

Entre os 8 artigos selecionados, podemos perceber que 4 foram publicados em 2018, sendo os demais distribuídos nos anos 2019, 2016, 2015 e 2010. Considerando os sítios

10 Classificação de periódico quadriênio 2013-2016. Disponível em: https://sucupira.capes.gov.br/sucupira/public/consultas/coleta/veiculoPublicacaoQualis/listaConsultaGeralPeriodi cos.jsf. Acesso em: 05 maio 2021. 
eletrônicos, 3 estudos foram selecionados na SciELO (PEREIRA et al., 2018; SILVA; SOUZA; CHECA, 2010; SILVA JÚNIOR; BOTH; OLIVEIRA, 2018). Notamos que o Journal of Physical Education (Qualis CAPES A1) é o periódico com maior frequência de artigos publicados ( 2 artigos).

A partir do próximo parágrafo, a nossa intenção é de abordar cada artigo selecionado para compor a amostra final, dessa forma apresentaremos os objetivos, metodologia, e seus principais resultados quanto à temática em tela, ou seja, formação e atuação de professores orientadores de ECS nos cursos de licenciatura em Educação Física. Seguiremos a ordem cronológica decrescente da data de publicação do trabalho.

Iniciando com Santos (2019), o estudo teve como objetivo apresentar e refletir a respeito das experiências no ECS I do curso de Educação Física da Universidade Federal do Pará (UFPA). O método adotado foi relato de experiência descritivo-analítico, sendo as experiências realizadas em uma instituição de ensino pública municipal.

O autor aponta alguns contextos limitantes do ECS, correspondendo tanto à escola, quanto à organização desse componente curricular ofertado pela instituição formadora. $\mathrm{O}$ autor menciona, dentre outros aspectos, que são notórias as dificuldades no planejamento desse componente curricular, interferindo na escolha das escolas e, consequentemente, no início das vivências.

Nesse primeiro estudo percebemos que os professores orientadores precisam manter o diálogo com os estagiários e com os professores supervisores da escola, uma vez que a articulação de ideias entre esses agentes pode evitar futuras frustrações das experiências vivenciadas, ou contribuir no enfrentamento de possíveis problemas que forem surgindo ao longo das atividades do ECS.

Por sua vez, o estudo de Pereira et al. (2018) objetivou analisar as ações formativas dos estudantes estagiários de um curso de licenciatura em Educação Física. Participaram 22 estudantes, distribuídos no ECS III, IV e V. O estudo foi caracterizado como descritivo e de abordagem qualitativa. Para coleta das informações, os autores utilizaram um questionário com perguntas subjetivas, sendo recorrida, posteriormente, à análise de conteúdo.

Os estagiários participantes do estudo apontaram diferentes aspectos que poderiam ser aprimorados para melhoria da qualidade das atividades realizadas. Exemplo disso, quanto ao caráter teórico-prático dos componentes curriculares do curso de formação, os estagiários 
destacam um distanciamento da realidade do contexto escolar, além da "dissociação entre a teoria e prática" e a prioridade de alguns componentes curriculares serem voltados para a aprendizagem de gestos técnicos dos esportes e pouca articulação entre as disciplinas do curso.

Os autores destacam que embora o ECS tenha proporcionado experiências fundamentais na formação inicial dos estudantes, ainda há diferentes aspectos do curso de formação que precisam ser aprimorados para oportunizar a qualidade dessas experiências, uma vez que as atividades de planejamento e a organização didática ainda são apresentadas pelos estagiários como uma das maiores dificuldades. Ademais, houve uma boa interação com o professor orientador e com o professor supervisor.

O terceiro estudo é de autoria de Silva Júnior, Both e Oliveira (2018), o qual se propôs a analisar as configurações e as relações estabelecidas na universidade e na escola, assim como entre os estagiários e os agentes da escola no que diz respeito às atividades do ECS na formação inicial de professores de Educação Física. É um estudo exploratório, com abordagem qualitativa e quantitativa. Participaram 63 professores da Educação Básica que lecionam a disciplina de Educação Física e 90 estudantes de Educação Física da Universidade Estadual de Maringá (UEM).

Para coletas das informações os autores fizeram o uso de um questionário e para análise das informações coletadas utilizaram o software SPSS para os dados quantitativos e o NVivo 10 para as informações qualitativas. Entre os resultados dessa investigação, foi apontado como um dos problemas a falta de supervisão dos professores orientadores das instituições formadoras. Essa realidade pode muitas vezes estar relacionada com as condições oferecidas para esses professores, sendo uma delas o quantitativo elevado de orientandos/estagiários por cada professor orientador, assim como veremos mais a frente na discussão do estudo de Silva, Souza e Checa (2010).

Quanto ao estudo de Almeida e Moreira (2018), foi traçado como objetivo identificar quais os saberes/conhecimentos mobilizados pelos professores de ECS nos cursos de licenciatura em Educação Física do Estado de Mato Grosso. Trata-se de um estudo de caráter descritivo e de abordagem qualitativa, tendo como participantes 24 professores que atuam no ECS, distribuídos em 10 cursos situados no contexto da investigação. Para coleta das informações foi utilizada entrevista semiestruturada, e após a transcrição dos áudios foram definidas categorias de codificação. 
De acordo com os autores, a formação inicial de professores requer dos agentes envolvidos, tanto dos professores como dos estudantes, a constituição de saberes necessários para atender as demandas recorrentes nos sistemas educacionais, "em relação aos aspectos éticos, coletivos, comportamentais, emocionais, dentre outros" (ALMEIDA; MOREIRA, 2018, p.145).

Os autores apresentam como referencial teórico os escritos de Shulman (2005) $)^{11}$, Tardif $^{12}$ (2012) e Gauthier e colaboradores $(2006)^{13}$. Estes teóricos discutem os conhecimentos e/ou saberes necessários à prática docente. Após as análises, Almeida e Moreira (2018, p.153) evidenciaram 4 categorias correspondentes aos saberes/conhecimentos docentes: a) "constituição da docência no ECS", b) "satisfação na atuação docente", c) "aprendizado da docência no ECS", e d) "características necessárias à docência no ECS".

Os professores de ECS que participaram da pesquisa também apontaram motivos que os levaram a ser professor desse componente curricular, sendo alguns deles: a) pela sua aproximação com a escola e com a docência, b) via processo seletivo e concurso, c) por convite da instituição, d) por necessidade e deficiência do curso, e e) por ter experiências anteriores com o ECS.

Além disso, Almeida e Moreira (2018, p.167) identificaram que os saberes/conhecimentos recorrentes no cotidiano da profissão docente, os chamados saberes/conhecimentos práticos ou experienciais; os saberes da organização e funcionamento das escolas; os saberes disciplinares e curriculares são os mais mobilizados pelos professores de ECS.

No estudo de Isbarrola e Copetti (2018), ao analisar as percepções positivas e negativas dos estagiários nas experiências no ECS na Educação Infantil, foi realizada uma análise documental (no total de 28 relatórios) a partir dos relatórios finais dos estudantes no ECS. Para análise das informações coletadas as autoras utilizaram análise de conteúdo de Bardin (2011) ${ }^{14}$.

\footnotetext{
${ }^{11}$ SHULMAN, L. S. Conocimiento y enseñanza: fundamentos de la nueva reforma. Revista de currículum y formación del professorado, v. 9, n. 2, p.1-30, 2005.

12 TARDIF, M. Saberes docentes e formação profissional. 14. ed. Petrópolis, RJ: Vozes, 2012.

${ }^{13}$ GAUTHIER, C. e colaboradores. Por uma teoria da pedagogia: pesquisas contemporâneas sobre o saber docente. 2. ed. ljuí, RS: Unijuí, 2006.

${ }^{14}$ BARDIN, L. Análise de conteúdo. São Paulo: Edições 70, 2011.
} 
Quanto aos professores orientadores, os autores mencionam que as suas contribuições são indispensáveis na atuação dos alunos no contexto escolar, sendo alguns dos seus principais papéis: a troca de experiência, complementação teórica, críticas construtivas acerca das ações desenvolvidas pelos estagiários.

No que diz respeito às percepções dos estagiários, evidenciaram pontos positivos e negativos. Como exemplo de aspectos positivos, as autoras alegaram a importância do professor orientador para que tivesse uma experiência em uma de suas aulas, assim como podemos perceber em uma das colocações de um participante [...] infelizmente a professora orientadora não estava presente nessa, a aula foi muito boa graças aos conselhos que ela deu [...] (ISBARROLA; COPETTI, 2018, p.212). As autoras também afirmam que a análise e o feedback de um profissional experiente e que não esteja influenciado pelo contexto, pode contribuir na correção de detalhes não identificados antes e que podem interferir no desenvolvimento das atividades.

Por outro lado, como pontos negativos as autoras identificaram nos relatórios algumas colocações dos alunos quanto à necessidade de uma maior frequência dos professores orientadores nas observações das aulas. Além disso, os estagiários alegaram como ponto negativo o nervosismo e ansiedade ao serem supervisionados. Muitos estagiários, até mesmo os professores orientadores, não têm o discernimento do principal papel das "supervisões", termo este que denota autoridade, mas que na prática remete à interação entre os agentes envolvidos no ECS, como também partilha de saberes e outras ações necessárias para o desenvolvimento acadêmico e profissional dos envolvidos. Para melhor esclarecer o papel do professor orientador, as autoras recorrem ao escrito de Pimenta e Lima (2012, p.114 apud ISBARROLA; COPETTI, p.213), onde afirmam que as supervisões "requerem aproximação e distanciamento, partilha de saberes, capacidade de complementação, avaliação, aconselhamento, implementações de hipóteses de solução para os problemas que, coletivamente, são enfrentados pelos estagiários".

No que concerne o estudo de Souza Neto, Sarti e Benites (2016, p.311), os autores discutem os desafios dos professores orientadores da instituição de ensino formadora e dos professores colaboradores das escolas frente à "difícil tarefa de compreender a prática de ensino no tocante à composição da identidade docente no âmbito da Educação Física e da Pedagogia". As reflexões tecidas pelos autores nesse ensaio partiram das experiências como orientadores de 
ECS na formação inicial desses dois cursos e da literatura especializada sobre a temática.

Um dos aspectos que mais chamou atenção na leitura desse escrito foi a afirmação de que muitos professores supervisores traçam atividades manuais ou técnicas para os estagiários desempenharem, tendo a intenção de "passar o tempo". Esta situação é uma realidade dos ECS na formação de professores e que muitas vezes vai de encontro aos ensinamentos dos professores orientadores. Tal realidade pode ser resultado da não definição dos papéis dos estagiários, professores orientadores e supervisores. Também como reflexo do não esclarecimento desses papéis, os autores mencionam que é comum os estagiários escolherem a escola para realização dos ECS por critérios individuais, bem como a partir de orientações gerais realizadas pelo professor orientador. Os autores concluem que "o estágio na perspectiva de uma iniciação profissional permite pensar a universidade e a escola como lugares de formação, uma estrada de mão dupla entre professores e estudantes, docência e instituições formadoras" (SOUZA NETO; SARTI; BENITES, 2016, p.321).

O próximo estudo a ser discutido foi realizado por Zuluaga (2015a), o qual teve como objetivo discutir o ECS na formação de professores de Educação Física na Colômbia, Brasil, Argentina e Chile, em especial compreender as orientações pedagógicas quanto aos processos avaliativos no ECS. Trata-se de um estudo de caso múltiplo, em que foi adotado o método histórico-descritivo-hermenêutico e abordagem qualitativa, a partir dos documentos oficiais.

O autor destaca que a formação docente é influenciada por múltiplos fatores, como modelos e tendências adquiridos ao longo das "[...] suas experiências, conhecimentos e estudos obtidos na vida acadêmica, educativa, social, pessoal em geral [...]" (ZULUAGA, 2015a, p.60). Para tanto, os processos avaliativos são imprescindíveis para efetividade das experiências vivenciadas no ECS, principalmente quando se trata de uma avaliação colaborativa que envolve os estagiários, professores orientadores e professores supervisores, e que exige conhecimentos de práticas e tipos de avaliação.

Chegando ao oitavo e último trabalho selecionado, discutiremos o estudo de Silva, Souza e Checa (2010) em que foi realizado um diagnóstico da dinâmica e aplicação da supervisão dos ECS na graduação e licenciatura em Educação Física a partir das resoluções CNE/CP ${ }^{15}$ no 01 e

\footnotetext{
${ }^{15}$ Conselho Nacional de Educação/Conselho Pleno.
} 
02/2002, no 07/2004 e n.02/2007. A pesquisa se caracteriza como descritiva e de abordagem qualitativa, tendo como participantes 7 docentes que lecionavam no ECS do curso de Educação Física de 6 instituições diferentes situadas em São Paulo. Para coleta das informações, os autores utilizaram entrevista semiestruturada, sendo recorrida nas análises dos dados à técnica de análise de conteúdo.

Os autores constataram um elevado número de estagiários por cada professor orientador, sendo uma estimativa de 100 a 160 orientandos por professor, o que pode interferir de forma negativa na qualidade das orientações. Além disso, alertam que os professores a partir das condições de trabalhos, minimizam seu papel nas orientações de ECS ao focalizar em aspectos burocráticos, como a verificação de preenchimento de planilha quanto à carga horária mínima exigida para aprovação, bem como a identificação de assinaturas e sua originalidade.

\section{Análises das dissertações e teses: BDTD e catálogo de teses e dissertações da CAPES}

A partir da apresentação dos artigos quanto ao objetivo, metodologia, e seus principais resultados, iremos discutir agora essas mesmas características iniciando pelas dissertações de mestrado e na sequência as teses de doutorado que foram selecionadas. Logo abaixo, no Quadro 3, iniciamos com as análises das dissertações.

Quadro 3 - Autor/ano, programa de pós-graduação e seu conceito Qualis CAPES e o título das dissertações de mestrado selecionadas.

\begin{tabular}{|c|c|c|c|}
\hline Autor (ano) & $\begin{array}{c}\text { Programa de pós-graduação } \\
\text { (PPG) }\end{array}$ & $\begin{array}{c}\text { Conceito } \\
\text { CAPES }^{\mathbf{1 6}}\end{array}$ & Título \\
\hline Silva (2018) & $\begin{array}{c}\text { PPG em Educação da } \\
\text { Universidade Federal de } \\
\text { Pelotas - UFPel }\end{array}$ & $\begin{array}{l}\text { O estágio curricular supervisionado na ótica } \\
\text { de egressos de um curso de licenciatura em } \\
\text { Educação Física }\end{array}$ \\
\hline Horiye (2018) & $\begin{array}{c}\text { PPG em Educação da } \\
\text { Universidade Estadual de } \\
\text { Londrina - UEL }\end{array}$ & Nota 4 & $\begin{array}{l}\text { O estágio Supervisionado em Educação } \\
\text { Física e Letras-Português da UEL: desafios e } \\
\text { possibilidades }\end{array}$ \\
\hline
\end{tabular}

\footnotetext{
${ }^{16}$ Disponível em:<http://portal.mec.gov.br/docman/setembro-2018-pdf/97581-pces487-18/file>.
} 


\begin{tabular}{|c|c|c|c|}
\hline $\begin{array}{c}\text { Bisconsini } \\
(2013)^{17}\end{array}$ & $\begin{array}{c}\text { PPG Associado em Educação } \\
\text { Física da } \\
\text { Universidade Estadual de } \\
\text { Maringá e Universidade } \\
\text { Estadual de Londrina -UEM/ } \\
\text { UEL }\end{array}$ & Nota 4 & $\begin{array}{l}\text { Formação inicial para docência: relações } \\
\text { entre estágio supervisionado, universidade } \\
\text { e escola. }\end{array}$ \\
\hline $\begin{array}{c}\text { Kronbauer } \\
\text { (2013) }\end{array}$ & $\begin{array}{c}\text { PPG em Educação da } \\
\text { Universidade Federal de Santa } \\
\text { Maria - UFSM }\end{array}$ & Nota 4 & $\begin{array}{l}\text { O curso de licenciatura em Educação Física: } \\
\text { as contribuições dos estágios curriculares } \\
\text { supervisionados para a formação de } \\
\text { professores reflexivos }\end{array}$ \\
\hline Silva (2012) & $\begin{array}{c}\text { PPG Associado em Educação } \\
\text { Física da } \\
\text { Universidade Estadual de } \\
\text { Maringá e Universidade } \\
\text { Estadual de Londrina -UEM/ } \\
\text { UEL }\end{array}$ & Nota 4 & $\begin{array}{l}\text { O estágio supervisionado na Formação } \\
\text { inicial de licenciados em Educação física no } \\
\text { Paraná }\end{array}$ \\
\hline $\begin{array}{l}\text { Quaranta } \\
\text { (2011) }\end{array}$ & $\begin{array}{l}\text { PPG em Educação Física da } \\
\text { Universidade Federal } \\
\text { de Santa Catarina - UFSM }\end{array}$ & Nota 6 & $\begin{array}{l}\text { Formação de professores de Educação Física } \\
\text { na modalidade de educação a distância: } \\
\text { experiências docentes no estágio } \\
\text { supervisionado }\end{array}$ \\
\hline Nunes (2010) & $\begin{array}{c}\text { PPG em Ciências do } \\
\text { Movimento Humano da } \\
\text { Universidade Federal do Rio } \\
\text { Grande do Sul - UFRGS }\end{array}$ & Nota 6 & $\begin{array}{l}\text { Os estágios docência e a formação de } \\
\text { professores em Educação Física: um estudo } \\
\text { de caso no curso de licenciatura da } \\
\text { ESEF/UFRGS }\end{array}$ \\
\hline Montiel (2010) & $\begin{array}{l}\text { PPG em Educação Física da } \\
\text { Universidade } \\
\text { Federal de Pelota - UFPel }\end{array}$ & Nota 4 & $\begin{array}{l}\text { Os Estágios Curriculares Supervisionados } \\
\text { nos cursos de licenciatura em } \\
\text { Educação Física do Rio Grande do Sul: } \\
\text { impacto das } 400 \text { horas }\end{array}$ \\
\hline Agostini (2008) & $\begin{array}{c}\text { PPG em Educação da } \\
\text { Universidade Federal de Santa } \\
\text { Maria - UFSM }\end{array}$ & Nota 4 & $\begin{array}{l}\text { A organização e o desenvolvimento de } \\
\text { estágios curriculares em cursos de } \\
\text { licenciatura da UFSM: envolvimentos de } \\
\text { estagiários e orientadores }\end{array}$ \\
\hline
\end{tabular}

Fonte: Os autores.

Entre as dissertações de mestrado selecionadas apenas uma foi por meio das buscas no Catálogo de Teses e Dissertações da CAPES (BISCONSINI, 2013). Quanto à temporalidade, as mais recentes são a de Silva (2018) e Horiye (2018). Em relação aos programas de pós-graduação (PPG) em que essas produções estão vinculadas, apresenta-se com maior frequência (2 dissertações) o PPG Associado em Educação Física da Universidade Estadual de Maringá e Universidade Estadual de Londrina - UEM/UEL; e o PPG em Educação da Universidade Federal de Santa Maria - UFSM.

No que diz respeito ao conceito CAPES, dois programas possuem conceito 6 (PPG em Educação Física da Universidade Federal de Santa Catarina - UFSM e PPG em Ciências do

17 Único estudo selecionado do Catálogo de Teses e Dissertações da CAPES. 
Movimento Humano da Universidade Federal do Rio Grande do Sul - UFRGS), sendo que apenas um apresenta-se com o conceito 5 (PPG em Educação da Universidade Federal de Pelotas UFPel), e os demais com o conceito 4. Destacamos também que dos 7 programas de pósgraduação em que essas dissertações estão distribuídas, 3 são em educação.

Iniciaremos a exploração das dissertações selecionadas quanto aos objetivos, metodologia e os principais resultados a partir do estudo de Silva (2018) que discutiu sobre o ECS no curso de Educação Física na modalidade presencial da Universidade Federal de Pelotas (UFPel). A pesquisa foi caracterizada como exploratória e com abordagem qualitativa, utilizando para coleta de dados um questionário com perguntas objetivas e subjetivas, sendo aplicado aos egressos do curso.

Quanto ao professor orientador, os participantes além de mencionarem a sua importância, destacaram que tiveram pouco acompanhamento por parte desses professores. 0 autor menciona que essa é uma realidade dos cursos de formação de professores, o que pode ser efeito das condições oferecidas para esses professores, como exemplo, a quantidade elevada de estagiários para orientar; o deslocamento com os próprios recursos financeiros até a escola onde se encontra os estagiários e a carga horária insuficiente para deslocamento até as escolas. Alguns participantes também destacaram a falta de vontade de alguns professores, tanto das escolas, como da instituição formadora, além do despreparo para lecionar o componente curricular ECS.

A segunda dissertação selecionada é de autoria de Horiye (2018), em que objetivou identificar as dificuldades dos estudantes de Educação Física e Letras-Português da Universidade Estadual de Londrina (UEL) na realização do estágio supervisionado. O estudo foi caracterizado como descritivo e de abordagem qualitativa, tendo o questionário e entrevista estruturada como técnicas de coleta de dados.

Uma das principais evidências encontradas pelo autor é o distanciamento entre a universidade e a escola, em que os componentes curriculares dos cursos não dialogam com a realidade das escolas. No que diz respeito aos participantes representantes do curso de Educação Física, quando indagados sobre as contribuições do professor orientador, a maioria dos estudantes (16 estudantes) responderam que contribuem "bastante". No entanto, quando perguntados em relação à frequência que o estagiário discutiu com o professor orientador sobre 
os conteúdos e as metodologias, a maioria dos estudantes (16 estudantes) afirmou que "às vezes". Cabe destacar que houve situações em que não ocorreu orientações do professor da instituição de ensino, principalmente quando o estagiário desenvolve as atividades de ECS em outra cidade.

O estudo de Bisconsini (2013) objetivou mapear tanto a estrutura, como o desenvolvimento do estágio em diferentes cursos de licenciatura de uma Instituição de Ensino Superior (IES) pública, sendo um desses cursos de Educação Física. A autora caracteriza a pesquisa como sendo descritiva e de abordagem qualitativa. Para coleta de dados foi utilizado um questionário (perguntas objetivas e subjetivas) e uma entrevista semiestruturada.

Sobre o professor orientador, a autora evidenciou a importância do acompanhamento aos estagiários nas escolas durante suas práticas; a sobrecarga de trabalho; o pouco tempo para atender a todos os estagiários; e a necessidade de maior auxílio na escolha dos conteúdos a serem desenvolvidos pelos estagiários. Bisconsini (2013) ainda alerta sobre a necessidade de criar momentos no decorrer da disciplina que promova o diálogo entre todos os envolvidos, a fim de melhor direcionar as atividades desenvolvidas pelos estagiários.

Também nos debruçamos sobre o estudo Kronbauer (2013), o qual objetivou analisar o modo que os estudantes do curso de Educação Física caracterizam as suas reflexões sobre as práticas pedagógicas no ECS. Trata-se de um estudo de caso, adotando uma abordagem qualitativa. Participaram da pesquisa estudantes que já cursaram três componentes curriculares de ECS. As coletas de dados ocorreram por meio de entrevistas semiestruturada, sendo analisadas por meio da análise de conteúdo.

Um dos resultados apontado pela autora diz respeito o distanciamento entre as disciplinas do curso de formação com a realidade escolar, bem como as metodologias de alguns professores que não atendem às demandas contemporâneas de educação, sendo ancoradas em correntes tradicionais que não prevalecem a criticidade e a constituição do profissional reflexivo.

Por sua vez, Silva (2012) discutiu como se concretiza o ECS em cursos de licenciatura em Educação Física no Norte do Paraná a partir das Resoluções CNE/CP nº 01 e 02/2002 e CNE/CES $n^{\circ} 07 / 2004$. O estudo foi caracterizado como descritivo e de abordagem qualitativa. Contou com a participação de coordenadores de estágio e egressos que estão atuando na Educação Básica. O autor recorreu ao regulamento do estágio das IES, entrevista e aplicação de questionário para 
coleta das informações. Após as informações coletadas, utilizou análise descritiva e análise de conteúdo.

O autor defende que escutar os estagiários, egressos e todos envolvidos no ECS, pode contribuir no aprimoramento das experiências ao longo dos componentes curriculares de estágio na formação inicial. Nessa perspectiva, os egressos sugeriram aumentar a quantidade de supervisões, bem como a sua qualidade. Dentre outras sugestões, os egressos sugeriram amenizar as exigências burocráticas e ampliação de discussões que promovam a troca de saberes. Frente a essa realidade, ressaltamos a importância de aumentar o número de docentes, consequentemente reduzir o número de estagiários por professor orientador.

No que diz respeito ao estudo de Quaranta (2011), foi traçado como objetivo compreender a percepção dos estagiários de um curso de Educação Física na modalidade de Educação a Distância (EAD) sobre as suas próprias experiências no ECS. A pesquisa foi caracterizada como do tipo de múltiplos casos a partir de relatos elaborados por estudantes. Além disso, foi realizada entrevista com os participantes, sendo as informações coletadas analisadas por meio da técnica de análise de conteúdo.

Uma das limitações mencionadas pelo autor foi relacionada à supervisão tanto pela instituição à distância, quanto do polo de apoio presencial. Uma das participantes relatou que em virtude de não terem sidos supervisionados pelo professor orientador da instituição formadora, as experiências foram mobilizadas entre os estudantes, elaborando uma espécie de "supervisão" entre os estagiários.

Nunes (2010) analisou o ECS do curso de licenciatura da Escola de Educação Física da Universidade Federal do Rio Grande do Sul (ESEF/UFRGS). A autora discute as influências das Diretrizes Curriculares Nacionais para a formação de professores da Educação Básica no desenvolvimento do ECS na formação inicial em Educação Física. Para tanto, foram analisados documentos legais, bem como referentes ao estágio ofertado da própria instituição, assim como foram entrevistados alunos dessa instituição que realizaram estágio no Ensino Médio.

Dentre outros achados, cabe destacar sobre as estratégias de orientações, em que os entrevistados lamentaram a ausência de supervisão, assim como de diálogo sobre os métodos de ensino e dificuldades encontradas no campo do estágio. Outro resultado que merece destaque diz respeito às diferentes formas de conduzir o componente curricular ECS por parte 
dos professores orientadores. Embora os entrevistados percebam que isso é um ponto positivo, pois pode contribuir para uma maior diversidade de experiências quanto aos métodos de ensino, eles relatam que podem ficar desorientados por não saber a melhor forma de contemplar as expectativas desses professores orientadores. Constatou-se ainda que a carga horária não é atendida conforme as orientações da legislação.

Próximo da linha de raciocínio de Nunes (2010), o trabalho de Montiel (2010) analisou o impacto da legislação pertinente ao estágio e a formação de professores no desenvolvimento do ECS nos cursos de Educação Física do Rio Grande do Sul (RS). Configura-se como uma pesquisa analítica, descritiva e comparativa. Para tanto, foram utilizados documentos que orientam os cursos e o estágio, aplicação de questionários aos professores orientadores e coordenadores dos cursos, análise documental do Projeto Pedagógico do Curso (PPC). A análise dos dados foi realizada mediante descrição e interpretação das informações coletadas, bem como o uso de análise de conteúdo.

Encontram-se como um dos maiores impactos, o aumento de estudantes estagiando nas escolas, o que elevou o número de estagiário por professor orientador. Somado a essa realidade, têm as diferentes atribuições empregadas a esse profissional em que a carga horária não atende todas as exigências. Outro aspecto que a autora chama a atenção é o diálogo que precisa existir entre o professor orientador e o professor supervisor para que seja possível direcionar as práticas dos estagiários na escola, como também a importância do acompanhamento e avaliação por todos os professores envolvidos nesse processo.

Chegando à exploração da última dissertação selecionada, iremos analisar o escrito de Agostini (2008) em que teve a intenção de contribuir com o melhor desenvolvimento dos componentes curriculares de estágio, partindo do questionamento de como se configura os ECS dos cursos de licenciatura da Universidade Federal de Santa Maria (UFMS), sendo um desses cursos o de Educação Física. O autor fez o uso dos PPC dos cursos investigados, como também da legislação sobre a formação de professores, aplicação de um questionário e grupos de discussões com os estagiários. Já com os professores orientadores de estágio foi realizada entrevista estruturada.

Um dos resultados positivos quanto aos estágios no curso de Educação Física e que pertence ao professor orientador, trata-se do bom relacionamento com os estagiários. Além 
disso, os estudantes destacaram como ponto positivo, o diálogo, compreensão da realidade e o auxílio frente às dificuldades. Por outro lado, a ausência nas supervisões nas escolas foi mencionada como um dos pontos negativos. Ou seja, mais uma vez a ausência de supervisões aparece como um dos problemas no desenvolvimento do ECS no curso de formação de professor de Educação Física.

Com o quantitativo menor de trabalhos selecionados em comparação às dissertações de mestrado apresentadas anteriormente, apresentaremos a seguir, no Quadro 4, algumas características das 5 teses de doutorado selecionadas. Na sequência demonstraremos as características a respeito dos objetivos, metodologia e principais resultados.

Quadro 4 - Autor/es, ano de defesa, programa de pós-graduação e seu conceito Qualis CAPES e o título das teses de doutorado selecionadas.

\begin{tabular}{|c|c|c|c|}
\hline $\begin{array}{l}\text { Autor } \\
\text { (ano) }\end{array}$ & Programa de pós-graduação (PPG) & $\begin{array}{c}\text { Conceito } \\
\text { CAPES }\end{array}$ & Título \\
\hline $\begin{array}{l}\text { Silva Júnior } \\
\text { (2016) }\end{array}$ & $\begin{array}{c}\text { Pós-Graduação } \\
\text { Associado em Educação Física - } \\
\text { UEM/UEL }\end{array}$ & Nota 4 & $\begin{array}{l}\text { Configurações e relações estabelecidas no } \\
\text { estágio curricular supervisionado na } \\
\text { formação inicial de professores de educação } \\
\text { física }\end{array}$ \\
\hline $\begin{array}{l}\text { Isse } \\
(2016)^{18}\end{array}$ & $\begin{array}{c}\text { PPG em Ciências do Movimento } \\
\text { Humano da Universidade Federal } \\
\text { do Rio Grande do Sul }\end{array}$ & Nota 6 & $\begin{array}{l}\text { O estágio supervisionado na formação de } \\
\text { professores de Educação Física: saberes e } \\
\text { práticas dos estudantes-estagiários }\end{array}$ \\
\hline $\begin{array}{l}\text { Zuluaga } \\
\text { (2015b) }\end{array}$ & $\begin{array}{l}\text { Programa de Pós-Graduação em } \\
\text { Ciências da Motricidade (pedagogia } \\
\text { da motricidade humana) } \\
\text { Universidade Estadual Paulista } \\
\text { “Júlio de Mesquita Filho" }\end{array}$ & Nota 5 & $\begin{array}{l}\text { Orientações pedagógicas no estágio } \\
\text { supervisionado de Educação física na } \\
\text { Colômbia, Brasil, Argentina e Chile }\end{array}$ \\
\hline $\begin{array}{l}\text { Aroeira } \\
(2009)\end{array}$ & $\begin{array}{c}\text { PPG em Educação da Faculdade de } \\
\text { Educação da Universidade de São } \\
\text { Paulo }\end{array}$ & Nota 5 & $\begin{array}{l}\text { O estágio como prática didática e } \\
\text { colaborativa: a produção de saberes por } \\
\text { futuros professores }\end{array}$ \\
\hline $\begin{array}{l}\text { Scherer } \\
(2008)\end{array}$ & $\begin{array}{l}\text { PPG em Educação da Universidade } \\
\text { Federal do Rio Grande do Sul }\end{array}$ & Nota 6 & $\begin{array}{l}\text { O desafio da mudança na formação inicial de } \\
\text { professores: o estágio curricular no curso de } \\
\text { licenciatura em Educação Física }\end{array}$ \\
\hline
\end{tabular}

Fonte: Os autores.

As teses mais recentes sobre o tema investigado são de 2016 (2 teses), sendo uma delas selecionada a partir das buscas no Catálogo de Teses e Dissertações da CAPES (ISSE, 2016). Quanto aos PPG, 2 tem conceito Qualis CAPES 6, sendo que outros dois PPG possuem conceito 5, e apenas 1 conceito 4. Vale mencionar que apenas 2 teses são de PPG na área de Educação.

18 Único estudo selecionado do Catálogo de Teses e Dissertações da CAPES. 
Agora que já selecionamos e apresentamos algumas características gerais das teses selecionadas, iniciaremos nos próximos parágrafos a discussão desses trabalhos quanto aos objetivos, metodologia e os principais resultados.

Seguindo a ordem de exposição do Quadro 4, Silva Júnior (2016) analisou como as configurações e as relações no ECS contribuem na autonomia de atuação, bem como na prática pedagógica dos estudantes de licenciatura em Educação Física da UEM. A tese foi elaborada seguindo um "Modelo Escandinavo", composto por cinco artigos considerados pelo autor como independentes.

O autor constatou algumas evidências quanto à configuração e relações no ECS, como sobrecarga de trabalho dos professores orientadores e o pouco diálogo entre esses professores com os demais professores que lecionam outros componentes curriculares do curso. Outro resultado que merece destaque é o pouco acompanhamento e supervisão dos professores orientadores da instituição formadora. De acordo com o autor, embora essa ausência possa ser justificada pela sobrecarga de trabalho demandada pela universidade, fica necessário que esses professores reflitam sobre o seu papel e as demandas requeridas por esse componente curricular.

O estudo de Isse (2016) teve como objetivo geral compreender de que forma ocorre a mobilização de saberes dos estudantes do curso de licenciatura em Educação Física no ECS no Ensino Médio. A pesquisa foi realizada em uma instituição comunitária de Ensino Superior do interior do Rio Grande do Sul, tendo como participantes 9 estudantes de licenciatura e utilizando entrevistas narrativas, observações, análise do PPC e grupo de discussão para coleta dos dados. Para melhor analisar as informações coletadas, foi realizada a triangulação entre as fontes do campo, as fontes teóricas e as interpretações da autora.

A autora destaca a importância do professor orientador como um agente fundamental tanto na observação, quanto no processo de reflexão e na organização das atividades docentes desempenhadas pelos estagiários. Dentre outros aspectos, a autora também menciona que o aprender com outro, quer seja com os professores supervisores ou professores orientadores, e até mesmo com os colegas de formação, foi uma das características identificadas no público investigado.

A tese de Zuluaga (2015b) propôs conhecer as orientações pedagógicas por parte dos professores de ECS no curso de Educação Física de 4 países (Colômbia, Brasil, Argentina e Chile). 
O autor fez o uso de documentos oficiais, bem como de entrevistas com professores orientadores das instituições formadoras, professores supervisores e estagiários-professores.

Dentre vários outros aspectos mencionados, a formação continuada tanto para o professor orientador, quanto para o professor supervisor é imprescindível para um melhor direcionamento das experiências dos estagiários. $O$ autor também destaca que um dos principais aspectos que interferem no trabalho docente são as experiências vivenciadas ainda como aluno (principalmente no período escolar) e os conhecimentos/saberes cognitivos. Desse modo, os saberes/conhecimentos pedagógicos e didáticos estudados na formação inicial poucos são recorridos no exercício da docência.

Quanto ao estudo de Aroeira (2009), o objetivo central foi analisar uma experiência de ECS com a intenção de apontar referenciais teórico-práticos para superação da racionalidade técnica na formação de professores. A investigação foi caracterizada como estudo do tipo de caso etnográfico, contendo abordagem qualitativa, e como participantes estudantes do curso de licenciatura em Educação Física do Centro Universitário Vila Velha localizado no estado de Espírito Santo. Como técnicas de coleta de dados foram utilizadas entrevistas, grupo focal e análise documental. Uma vez as informações coletadas, foram analisadas por meio da análise de conteúdo.

Entre outras evidências a autora menciona a importância da reflexão compartilhada entre todos os envolvidos nas atividades teóricas e práticas, tendo o orientador papel fundamental na aproximação e diálogo entre universidade e escola, bem como no apoio pedagógico.

Chegamos neste momento na última tese selecionada, em que Scherer (2008) discutiu sobre o quão um processo participativo no ECS influencia positivamente no desenvolvimento da autonomia e consistência crítico-reflexiva de estudantes de licenciatura em Educação Física. O autor adotou uma perspectiva da pesquisa participante e da investigação-ação. Em relação aos recursos para obtenção dos dados, o autor recorreu a uma entrevista semiestruturada, observação participante e diário de campo.

O autor considera o estágio como "espinha dorsal" dos cursos de formação de professores. Além disso, alerta para a necessidade de uma maior atenção para esse componente curricular, como exemplo a carga horária suficiente para supervisão e discussão com grupos de no máximo de 15 estagiários. 


\section{Considerações finais}

As produções analisadas discutem, embora não exclusivamente, a respeito de diferentes nuances da formação e atuação do professor orientador de ECS, podendo ser alocadas nos seguintes grupos: a) importância das supervisões para atuação do estagiário, b) relação professor orientador-estagiário-professor supervisor, c) qualidade das orientações do professor orientador, d) frequência de supervisões ou orientações, e) condições de trabalho do professor orientador.

Elucidamos que apenas quatro estudos discutem sobre os saberes necessários à prática docente no ESC, sendo dois com maior direcionamento para saberes das práticas de ensino dos estagiários e dois com a atenção nos saberes das práticas de ensino do professor supervisor de estágio. No que diz respeito aos aspectos técnicos metodológicos, percebemos que todas as produções selecionadas foram realizadas em uma temporalidade transversal. Quanto ao tipo de estudo, evidenciamos uma diversidade que nos permite destacar como exemplo os estudos de caráter descritivo, exploratório, documental, estudo de caso, estudo de caso múltiplo, estudo caso etnográfico, ensaio crítico, relato de experiência, pesquisa participante, investigação-ação e revisão sistemática. Por sua vez, constatamos uma prevalência de estudos que adotaram uma abordagem qualitativa.

Ressaltamos que o uso de diferentes instrumentos para coleta de dados, como questionário, entrevista, observação, observação participante, intervenção, documentos, grupo de discussão, grupo focal e diário de campo. Dessa maneira, prevaleceu o número de trabalhos que utilizaram a técnica de análise de conteúdo. Para as análises de dados poucos estudos recorreram a software, mas quando recorrido houve a preferência pelo Nvivo para análises qualitativas. Destacamos ainda que apenas um estudo utilizou estatística inferencial.

As diferentes realidades apontadas por esses estudos nos fizeram refletir sobre os desafios que permeiam o exercício da profissão do professor orientador de ECS, bem como a estrutura técnica metodológica utilizada pelos autores. Tais pesquisas também nos fizeram perceber a importância de estudos que problematizem a formação e atuação dos professores orientadores dos cursos de licenciatura em Educação Física no ECS, uma vez que são escassas as pesquisas que se focalizam integralmente a essa temática.

Salientamos que o pouco acompanhamento e supervisão dos professores orientadores 
podem descaracterizar o papel educativo do ECS, portanto, tornam-se urgentes discussões e estratégias a serem adotadas pelo colegiado dos cursos de formação e pelos demais setores das instituições de ensino, de modo a oportunizar condições necessárias para efetivação de diálogos, reflexões, direcionamento e redirecionamento da formação e atuação, tanto dos estagiários quanto dos professores orientadores.

Para enfrentar as diversas situações exigidas no ECS, as quais foram reveladas pelos estudos incluídos neste EQ, faz-se necessária a mobilização de saberes por parte dos professores orientadores, estagiários e professores supervisores. Ademais, ao evidenciarmos a escassez de estudo sobre o professor orientador, sugerimos pesquisas futuras, empíricas e/ou teóricas, que objetivem identificar como se constituem os processos formativos, saberes docentes e as práticas de ensino dos professores supervisores nas disciplinas de ECS.

\section{Referências}

AGOSTINI, S. A organização e o desenvolvimento de estágios curriculares em cursos de licenciatura da UFSM: envolvimentos de estagiários e orientadores. 2008. 281f. Dissertação (Mestrado em Educação) - Universidade Federal Santa Maria, Centro de Educação, Programa de Pós-Graduação em Educação, Santa Maria, 2008. Disponível em: https://repositorio.ufsm.br/handle/1/6847. Acesso em: 17 set. 2020.

ALMEIDA, F. F. V.; MOREIRA, E. C. Os saberes/conhecimentos mobilizados pelos professores de estágio curricular nos cursos de licenciatura em Educação Física no estado de Mato Grosso. Revista Cocar, v.12, n.24, p.144-170, 2018. Disponível em: https://periodicos.uepa.br/index.php/cocar/article/view/1896. Acesso em: 17 set. 2020.

AROEIRA, K. P. O estágio como prática dialética e colaborativa: a produção de saberes por futuros professores. 2009. 253f. Tese (Doutorado em Educação) - Faculdade de Educação. Universidade de São Paulo, 2009. Disponível em: https://www.teses.usp.br/teses/disponiveis/48/48134/tde-15092009-154600/en.php. Acesso em: 18 set. 2020.

BISCONSINI, C. R. Formação inicial para docência: relações entre estágio supervisionado, universidade e escola. 2013. 161f. Dissertação (Mestrado em Educação Física) - Universidade Estadual de Maringá, Centro de Ciências da Saúde, Programa de Pós-Graduação Associado em Educação Física, Maringá, 2013. Disponível em: http://repositorio.uem.br:8080/jspui/handle/1/5723. Acesso em: 17 set. 2020. 
BOOTE, D. N.; BEILE, P. Scholars before researchers: on the centrality of the dissertation literature review in research preparation. Educational Researcher, v.34, n.6, p.3-15, 2005.

BRASIL. Lei no 11.788, de 25 de setembro de 2008: Dispõe sobre o estágio de estudantes. Disponível em: http://www.normaslegais.com.br/legislacao/lei 11788.htm. Acesso em: 21 ago. 2020.

BRASIL. Instituto Nacional de Estudos e Pesquisas Educacionais Anísio Teixeira. Thesaurus Brasileiro da Educação. Disponível em:

http://pergamum.inep.gov.br/pergamum/biblioteca/pesquisa_thesauro.php?resolution2=1024 _1. Acesso em: 05 maio 2021.

GAMBOA, S. S. Pesquisa em educação: métodos e epistemologias. 2. ed. Chapecó: ARGOS, 2012.

GAUTHIER, C. et al. Por uma teoria da pedagogia: pesquisas contemporâneas sobre o saber docente. Ijuí: Unijuí, 1998.

GAUTHIER, C.; BISSONNETTE, S.; RICHARD, M. Ensino explícito e desempenho dos alunos: a gestão dos aprendizados. Petrópolis, RJ: Vozes, 2014.

HORIYE, E. Y. O estágio supervisionado em educação física e letras-português da UEL: desafios e possibilidades. 2018. 208f. Dissertação (Mestrado em Educação) - Universidade Estadual de Londrina, Centro de Educação, Comunicação e Artes, Programa de Mestrado em Educação da Universidade Estadual de Londrina, Londrina, 2018. Disponível em: http://www.uel.br/pos/mestredu/images/stories/downloads/dissertacoes/2018. Acesso em 17 set. 2020.

ISBARROLA, J. A.; COPETTI, J. Percepções de estagiários da educação física sobre o estágio supervisionado na educação infantil. Revista Exitus, v.8, n.2, p.189-218, 2018. Disponível em: http://www.ufopa.edu.br/portaldeperiodicos/index.php/revistaexitus/article/view/534. Acesso em: 04 maio 2021. Doi: https://doi.org/10.24065/2237-9460.2018v8n2ID534.

ISSE, S. F. O estágio supervisionado na formação de professores de educação física: saberes e práticas dos estudantes-estagiários. 2016. 234f. Tese (Doutorado em Ciências do Movimento Humano) - Programa de Pós-Graduação em Ciências do Movimento Humano, Universidade Federal do Rio Grande do Sul, 2016. Disponível em:

https://www.lume.ufrgs.br/handle/10183/151414. Acesso em: 18 set. 2020.

KRONBAUER, C. P. O curso de licenciatura em educação física: as contribuições dos estágios curriculares supervisionados para a formação de professores reflexivos. 2013. 140f. Dissertação (Mestrado em Educação) - Universidade Federal de Santa Maria, Centro de Educação, Programa de Pós-Graduação em Educação, Santa Maria, 2013. Disponível em: https://repositorio.ufsm.br/handle/1/7083. Acesso em: 17 set. 2020. 
MONTIEL, F. C. Os estágios curriculares supervisionados nos cursos de licenciatura em educação física do Rio Grande do Sul: impacto das 400 horas. 2010. 131f. Dissertação (Mestrado em Ciências) - Universidade Federal de Pelotas, Escola Superior de Educação Física, Curso de Mestrado em Educação Física, Pelotas, 2010. Disponível em: http://www.repositorio.ufpel.edu.br/handle/123456789/1849. Acesso em: 17 set. 2020.

NÓBREGA-THERRIEN, S. M.; THERRIEN, J. O estado da questão: aportes teóricos-metodológicos e relatos de sua produção em trabalhos científicos In: FARIAS, I. M. S.; NUNES, J. B. C.; NÓBREGA THERRIEN, S. M. (org.). Pesquisa científica para iniciantes: caminhando no labirinto. Fortaleza: EdUECE, 2010, p.33-51. (Coleção Métodos de Pesquisa).

NUNES, R. V. Os estágios de docência e a formação de professores em educação física: um estudo de caso no curso de licenciatura da ESEF/UFRGS. 2010. 110f. Dissertação (Mestrado em Ciências do Movimento Humano) - Universidade Federal do Rio Grande do Sul, Programa de Pós-Graduação em Ciências do Movimento Humano, Porto Alegre, 2010. Disponível em: https://www.lume.ufrgs.br/handle/10183/93379. Acesso em 17 set. 2020.

PEREIRA, S. G. P. et al. Trajetória de estudantes na formação inicial em educação física: o estágio curricular supervisionado em foco. Journal of Physical Education, v.29, p.1-12, 2018. Disponível em: https://periodicos.uem.br/ojs/index.php/RevEducFis/article/view/37734/751375139406. Acesso em: 04 maio 2021. DOI: https://doi.org/10.4025/jphyseduc.v29i1.2959.

PICONEZ, S. C. B. et al. A prática de ensino e o estágio supervisionado. Campinas: Papirus, Editora, 2012.

PIMENTA, S. G.; LIMA, M. S. L. Estágio e docência. 8. ed. São Paulo: Cortez, 2017.

QUARANTA, A. M. Formação de professores de educação física na modalidade de educação a distância: experiências docentes no estágio supervisionado. 2011. 207f. Dissertação (Mestrado em Educação Física) - Universidade Federal de Santa Catarina, Centro de Desportos, Programa de Pós-Graduação em Educação Física, Florianópolis, 2011. Disponível em:

https://repositorio.ufsc.br/handle/123456789/94945. Acesso em: 17 set. 2020.

SANTOS, C. A. F. Estágio curricular supervisionado em educação física: experiência e implicações para a formação de professores. Caderno de Educação Física e Esporte, v.17, n.2, p.1-9, 2019. Disponível em: http://e-

revista.unioeste.br/index.php/cadernoedfisica/article/view/22202. Acesso em: 05 maio 2021. DOI: http://dx.doi.org/10.36453/2318-5104.2019.v17.n2.p193.

SCHERER, A. O desafio da mudança na formação inicial de professores: o estágio curricular no curso de licenciatura em educação física. 2008. 210f. Tese (Doutorado em Educação) Programa de Pós-Graduação em Educação, Universidade Federal do Rio Grande do Sul, 2008. Disponível em: https://www.lume.ufrgs.br/handle/10183/13503. Acesso em 18 set. 2020. 
SILVA JÚNIOR, A. P. Configurações e relações estabelecidas no estágio curricular supervisionado na formação inicial de professores de educação física. 2016. 232f. Tese (Doutorado em Educação Física) - Programa de Pós-Graduação Associado em Educação Física, Universidade Estadual de Maringá, 2016. Disponível em:

http://repositorio.uem.br:8080/jspui/handle/1/2151. Acesso em 18 set. 2020.

SILVA, L. F. Estágio curricular supervisionado na ótica de egressos de um curso de licenciatura em educação física. 2018. 129f. Dissertação (Mestrado em Educação) - Universidade Federal de Pelotas, Faculdade de Educação, Programa de Pós-Graduação em Educação, Pelotas, 2018. Disponível em: http://www.repositorio.ufpel.edu.br/handle/prefix/4377. Acesso em: 17 set. 2020.

SILVA, S. A. P. S.; SOUZA, C. A. F.; CHECA, F. M. Situação do estágio supervisionado em IES privadas da grande São Paulo. Motriz: Revista de Educação Física, v.16, n.3, p.682-688, 2010. Disponível em:

https://www.periodicos.rc.biblioteca.unesp.br/index.php/motriz/article/view/3744. Acesso em: 04 maio 2021. DOI: http://dx.doi.org/10.5016/1980-6574.2010v16n3p682.

SILVA, S. L. P. O. O estágio supervisionado na formação inicial de licenciados em educação física no Paraná. 2012. 153f. Dissertação (Mestrado em Educação Física) - Universidade Estadual de Maringá, Centro de Ciências da Saúde, Programa de Pós-Graduação Associado em Educação Física UEM/UEL, Maringá, 2012. Disponível em:

http://repositorio.uem.br:8080/jspui/handle/1/2262. Acesso em: 17 set. 2020.

SILVA JÚNIOR, A. P.; BOTH, J.; OLIVEIRA, A. A. B. Configurações e relações estabelecidas no estágio curricular supervisionado de Educação Física. Journal of Physical Education, v.29, p.113, 2018. Disponível em:

https://periodicos.uem.br/ojs/index.php/RevEducFis/article/view/36081/751375137674.

Acesso em: 05 maio 2021. DOI: http://dx.doi.org/10.4025/jphyseduc.v29i1.2937.

SOUZA NETO, S.; SARTI, F. M.; BENITES, L C. Entre o ofício de aluno e o habitus de professor: os desafios do estágio supervisionado no processo de iniciação à docência. Movimento (ESEFID/UFRGS), v.22, n.1, p.311-324, 2016. Disponível em: https://seer.ufrgs.br/Movimento/article/view/49700/36619. Acesso em: 05 maio 2021. DOI: https://doi.org/10.22456/1982-8918.49700.

TARDIF, M. Saberes docentes e formação profissional. 16. ed. Petrópolis, RJ: Vozes, 2014.

ZABALZA, M. A. O estágio e as práticas em contextos profissionais na formação universitária. São Paulo: Cortez, 2014.

ZULUAGA, C. F A. Avaliação do estágio supervisionado (ES) em educação física: Colômbia, Brasil, Argentina e Chile. Lúdica Pedagógica, v.2, n.22, 2015a. Disponível em: https://revistas.pedagogica.edu.co/index.php/LP/article/view/2963. Acesso em: 05 maio 2021. DOI: https://doi.org/10.17227/01214128.2963. 
ZULUAGA, C. F. A. Orientações pedagógicas no estágio supervisionado de educação física na Colômbia, Brasil, Argentina e Chile. 2015b. 383f. Tese (Doutorado em Ciências da Motricidade) - Programa de Pós-Graduação em Ciências da Motricidade, Universidade Estadual Paulista, 2015. Disponível em: https://repositorio.unesp.br/handle/11449/139366. Acesso em: 18 set. 2020.

Recebido em fevereiro 2021.

Aprovado em junho 2021. 